\title{
Exploring Clinical Educator and Student Perspectives on the Implementation of the Calderdale Framework as a Model of Occupational Therapy Clinical Education in Australia: a Pilot Study
}

\author{
Linda J. Furness \\ Government of Queensland, Department of Health, mlfurness@bigpond.com \\ Anna Tynan \\ Government of Queensland, Department of Health, anna.tynan@health.qld.gov.au \\ Alison C. Pighills \\ Government of Queensland, Department of Health, alison.pighills@health.qld.gov.au
}

Follow this and additional works at: https://nsuworks.nova.edu/ijahsp

Part of the Medicine and Health Sciences Commons

\section{Recommended Citation}

Furness LJ, Tynan A, Pighills AC. Exploring Clinical Educator and Student Perspectives on the Implementation of the Calderdale Framework as a Model of Occupational Therapy Clinical Education in Australia: a Pilot Study. The Internet Journal of Allied Health Sciences and Practice. 2018 Jan 01;16(3), Article 10.

This Manuscript is brought to you for free and open access by the College of Health Care Sciences at NSUWorks. It has been accepted for inclusion in Internet Journal of Allied Health Sciences and Practice by an authorized editor of NSUWorks. For more information, please contact nsuworks@nova.edu. 


\title{
Exploring Clinical Educator and Student Perspectives on the Implementation of the Calderdale Framework as a Model of Occupational Therapy Clinical Education in Australia: a Pilot Study
}

\begin{abstract}
Purpose: This paper describes the exploration of clinical educator and student perspectives on the implementation of the Calderdale Framework (CF) as a model for pre-entry occupational therapy clinical placement. Setting: The study was undertaken within a regional health service in Queensland, Australia. The orthopaedic inpatient ward at the regional hospital and mixed inpatient and outpatient community based caseloads in rural hospitals were the focus of this study. Methods: The Calderdale Framework is a seven stage process which involves: engaging staff with the framework; identifying which clinical tasks are carried out within the service; analysing which tasks can be allocated to students; setting up supervision systems; developing Clinical Task Instructions (CTIs); providing competency training and assessment; and developing organisational systems to sustain the new ways of working. In the first week of placement, students were 'taught' background and theoretical information for nine Clinical Task Instructions. In the remainder of their placement they achieved competence in these tasks and implemented clinical interventions with patients. Results: Separate focus groups and in-depth interviews were used to explore clinical educator and student opinions about their experience of the application of the Calderdale Framework in clinical education. Five themes emerged from the data analysis: experience of new model; adjustment to change in approach to the placement model; impact of the Calderdale Framework Clinical Task Instructions; impact of the Calderdale Framework learning model on student confidence and impact of the Calderdale Framework placement model on service delivery. Conclusion: In this pilot study, the application of the Calderdale Framework in clinical education was supported by both clinical educators and students as a model that supported student learning and safe contribution to patient service delivery. The time invested in planning, resource development and implementing this application of the Calderdale Framework in clinical education has resulted in a model which can continue to be implemented within our health service and could be applied to other professions or replicated elsewhere.
\end{abstract}

\section{Author Bio(s)}

Linda J Furness, MPST, BOccThy, is an Occupational Therapy Clinical Education Officer within the Darling Downs Hospital and Health Service, and Lecturer with Griffith University, School of Allied Health Sciences.

Anna Tynan PhD, MIPH, BOccThy, is a Research Fellow with the Darling Downs Hospital and Health Service and an Honorary Research Fellow with The School of Public Health, The University of Queensland

Alison C Pighills, PhD, MSc, Grad Dip, Dip COT, is an Associate Professor in the College of Healthcare Sciences at James Cook University, Townsville, and a Principal Research Fellow in the Mackay Institute of Research and Innovation within the Mackay Hospital and Health Service, Queensland Health

\section{Acknowledgements}

This project has been funded by Allied Health Professionals' Office of Queensland, Department of Health, Queensland, Health Practitioner Research Scheme 2015-2017 and Toowoomba Hospital Foundation Research Scholarship. The authors acknowledge the occupational therapy staff at Toowoomba Hospital and participating occupational therapy students for their willingness to support this study, and the Directors of Occupational Therapy, Darling Downs Hospital and Health Service, the Calderdale Framework network Queensland Health and the Allied Health Professions' Office of Queensland. The authors wish to thank Ms Cate Fitzgerald, Queensland Health Statewide Clinical Education and Training Program Manager, Occupational Therapy, for her review of an earlier draft of this manuscript.

This manuscript is available in Internet Journal of Allied Health Sciences and Practice: https://nsuworks.nova.edu/ijahsp/vol16/iss3/10 


\title{
IUAHSP \\ The Internet Joưnal of Allied Health Sciences and Practice
}

Dedicated to allied health professional practice and education

Vol. 16 No. 3 ISSN 1540-580X

Exploring Clinical Educator and Student Perspectives on the Implementation of the Calderdale Framework as a Model of Occupational Therapy Clinical Education in Australia: a Pilot Study

Linda J. Furness

Anna Tynan

Alison C. Pighills

Government of Queensland, Department of Health

Australia

\begin{abstract}
Purpose: This paper describes the exploration of clinical educator and student perspectives on the implementation of the Calderdale Framework (CF) as a model for pre-entry occupational therapy clinical placement. Setting: The study was undertaken within a regional health service in Queensland, Australia. The orthopaedic inpatient ward at the regional hospital and mixed inpatient and outpatient community-based caseloads in rural hospitals were the focus of this study. Methods: The Calderdale Framework is a seven stage process which involves: engaging staff with the framework, identifying which clinical tasks are carried out within the service, identifying which clinical tasks are carried out within the service, analysing which tasks can be allocated to students, setting up supervision systems, developing Clinical Task Instructions (CTIs), providing competency training and assessment, and developing organisational systems to sustain the new ways of working. In the first week of placement, students were 'taught' background and theoretical information for nine Clinical Task Instructions. In the remainder of their placement, they achieved competence in these tasks and implemented clinical interventions with patients. Results: Separate focus groups and in-depth interviews were used to explore clinical educator and student opinions about their experience of the application of the Calderdale Framework in clinical education. Five themes emerged from the data analysis: experience of new model, adjustment to change in approach to the placement model, impact of the Calderdale Framework Clinical Task Instructions, impact of the Calderdale Framework learning model on student confidence, and impact of the Calderdale Framework placement model on service delivery. Conclusion: In this pilot study, the application of the Calderdale Framework in clinical education was supported by both clinical educators and students as a model that supported student learning and safe contribution to patient service delivery. The time invested in planning, resource development, and implementing this application of the Calderdale Framework in clinical education has resulted in a model which can continue to be implemented within our health service and could be applied to other professions or replicated elsewhere.
\end{abstract}

Key Words: Allied Health, Occupational Therapy, Clinical Education, Calderdale Framework 


\section{INTRODUCTION}

Clinical education placement models which support students' learning as novice practitioners, whilst maintaining safe patient service delivery, need to be examined due to multiple demands on professionals in an increasingly complex healthcare environment. The increased number of Occupational Therapy (OT) schools in Australia have created an increased demand for clinical placements to support student education, thus, different models of clinical education need to be developed. This study applies the Calderdale Framework (CF) as a model of clinical education in which students are taught agreed clinical skills which support their contribution to patient service delivery.

\section{Importance of Practice Education}

The World Federation of Occupational Therapists (WFOT) guidelines require occupational therapy students to complete 1000 hours of practice education prior to graduation. Practice education forms an integral part of the curriculum providing students with opportunities to apply theory and practical skills learned in the academic environment in the 'real-world' context of practice and to develop competence in areas listed in the placement assessment tool - the Student Practice Evaluation Form - Revised Edition (SPEF-R). ${ }^{1}$ The SPEF-R was developed through national consultation with stakeholder groups and is used as the clinical placement assessment tool by Australian universities. The tool covers eight areas of competence: professional behaviour, self-management skills, coworker communication, communication skills, documentation, information gathering, service provision, and service evaluation. ${ }^{2}$ Clear assessment guidelines are provided with a five-point rating scale and behavioural descriptors for competency skill development. ${ }^{2}$

\section{Current Issues in Clinical Education}

In Queensland, Australia, there has been an increase in occupational therapy programs, with five entry-level programs in the state capital area of Brisbane alone. ${ }^{1}$ This equates to a requirement of over 480 placement blocks of longer than four weeks duration during Semester 1,2018. ${ }^{3}$ Similar increases have been noted in student numbers in other allied health courses within Queensland. Therefore, Clinical Educators (CEs) are being increasingly required to support clinical placements in their work settings while also maintaining the delivery of high quality, safe clinical services to patients. ${ }^{4}$ The need for efficient clinical education placement models, which support student skill acquisition, while meeting placement demand and enabling CEs to meet the demands of service delivery are necessary.

\section{Teaching and Learning in Clinical Education}

Dreyfus proposed a five-stage model to skill acquisition. ${ }^{5}$ This model of skill acquisition has been applied across nursing, medicine, and occupational therapy. ${ }^{6-8}$ Dreyfus noted the five stages of learning as: novice, advanced beginner, competent, proficient, and expert. ${ }^{5}$ Students could be considered novice practitioners as they have limited prior experience in the skill that they are learning. Characteristics of novice practitioners include the use of: rule-based decision making, analytical reasoning in their decision making, difficulty synthesising information to filter important information or prioritise relevant information, and reliance on objective facts and figures. $5,7,8$

To ensure novice student learners on clinical placements progress towards increased skill development, at the advanced beginner level, it is necessary to support the development of clinical reasoning skills. ${ }^{7}$ Advanced beginners are: starting to gain experience from real scenarios, increasingly able to sort through rules and information to determine relevance based on past experience, and increasingly capable of using both analytical reasoning and pattern recognition. ${ }^{5,7,8}$ They still require assistance to set priorities and work within guidelines. ${ }^{7}$ Clinical reasoning is defined by Schell and Schell as 'the process that practitioners use to plan, direct, perform, and reflect on client care." It is considered an important skill to acquire. ${ }^{9}$ Unsworth and Baker systematically reviewed literature on professional reasoning in occupational therapy. ${ }^{10}$ They noted that all reviewed studies reinforced the complex nature of developing clinical reasoning skills. ${ }^{10}$ Innovative approaches to support students to acquire clinical reasoning skills are required, along with an understanding of how placement experiences can promote skill acquisition and mastery. ${ }^{10}$

\section{Calderdale Framework in Clinical Education}

(c) The Internet Journal of Allied Health Sciences and Practice, 2018 
The Calderdale Framework (CF) has been adopted by Queensland Health as a tool to support the delegation of clinical

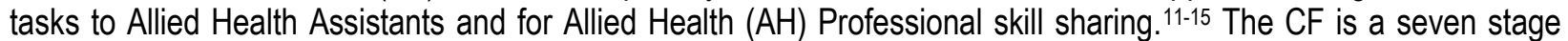
process which involves: engaging occupational therapists with the framework, identifying which clinical tasks are carried out within the service, analyzing which tasks can be skill shared between professionals or delegated to support staff (task analysis), setting up supervision systems, developing Clinical Task Instructions (CTIs), providing competency training and assessment, and developing organisational systems to sustain the new ways of working (Table 1). ${ }^{14,15} \mathrm{~A}$ pilot study examining the application of CF in clinical education has been described previously. ${ }^{16}$

Table 1. Calderdale Framework overview (adapted from Smith and Duffy, ${ }^{14} \&$ Furness, Pighills, Ducat, and Tynan ${ }^{16}$ )

\begin{tabular}{|l|}
\hline Calderdale Framework Stages and focus \\
\hline Stage 1 \\
Awareness raising: \\
Engaging occupational therapists with the framework \\
\hline Stage 2 \\
Service analysis: \\
Identifying clinical tasks carried out in teams \\
\hline Stage 3 \\
Task analysis: \\
Deciding which tasks can be allocated to students \& managing risk \\
\hline Stage 4 \\
Competency identification: \\
Creating local CTls (competencies) to standardise how tasks are carried out \\
\hline Stage 5 \\
Supporting systems: \\
Establishing governance processes to support students \\
\hline Stage 6 \\
Training: \\
Providing structured training and competence assessment for student allocated \\
tasks \\
\hline Stage 7 \\
Sustaining: \\
Establishing systems to sustain the model of practice in the long term \\
\hline
\end{tabular}

CF utilizes a variety of learning approaches building on students' curriculum knowledge as well as new knowledge gained from placement experiences. The $\mathrm{CF}$ is applied to learning by doing and reflection during and after the teaching and learning process. Skill acquisition in the CF model involves active participation by students in a real-world clinical environment. In addition, the application of student knowledge (from curriculum and placement learning) supports competency development on placement and is guided by the application of the CF taught-modeled-competent learning approach. Finally, risk to patients from student clinical practices on placement is mitigated through ongoing risk assessment completed when decisions are made about which clinical tasks can be allocated to students. Only tasks considered safe and relevant are allocated to students and students are assessed as competent to perform a clinical task using the CTI prior to exposure to patients. CTIs are the competency training documents which describe the clinical task, how it is performed, and provide details for training in and assessing the task. A clinical reasoning tool is included in the CTI and serves as a training tool to support students in developing their clinical reasoning skills, noting factors they have considered and clinical reasoning leading to their decisions about providing a specific intervention.

The authors of this manuscript believe the CF model could support the progression of skill development of students as novice practitioners through the provision of a clinical reasoning tool to afford students a framework to support

(c) The Internet Journal of Allied Health Sciences and Practice, 2018 
development of clinical decision making and recommendations for future patient care. The 'taught' component of the model provides theoretical information and facts about the clinical skill for students who may have had limited or no exposure to the skill being taught. It provides information about procedures specific to the workplace context. CF training approaches and resources are designed to achieve consistent and repeatable outcomes. The CF is a clinical education model which is likely to be easily adaptable to regional service delivery. ${ }^{16}$ The current study draws on the concepts of learning transition from novice to expert practitioner and pairs this with a pragmatic approach to the development of clinical placement models which are supportive of the complexities of modern healthcare environments. The aim of this paper is to explore clinical educator and student perspectives on the implementation of the Calderdale Framework as a model of clinical education in regional and rural hospitals in Queensland, Australia.

\section{METHODS \\ Ethical Considerations}

This study was granted Human Research and Ethics Committee approval in 2013 (HREC/13/QTDD/80). The research team comprised individuals with backgrounds in research methodology, clinical education, and a CF practitioner. Written informed consent was obtained from all focus group discussion (FGD) and in-depth interview (IDI) participants. De-identified data were stored with pseudonyms used for FGD and IDI responses.

\section{Study Design}

A qualitative research design was used. This approach provided a way of exploring and understanding the perspective of participants and the meaning they ascribed to the research problem. ${ }^{17}$ Following completion of student placements, student and clinical educator perspectives on the implementation of the CF model were explored using in-depth interviews and focus group discussions.

\section{Study Setting}

The study was undertaken in 2016 within a regional health service in Queensland, Australia, comprising one regional and six rural teaching hospitals. This study took place at two locations in the health service: the orthopaedic inpatient ward at the regional hospital and a mixed inpatient and outpatient community-based caseload in one rural hospital

\section{Participants and Recruitment}

Purposeful sampling was used to identify study participants. Potential participants identified for inclusion in the study were occupational therapy clinical educators at one regional and six rural hospitals in the health service, and occupational therapy students completing clinical placements in these locations. Students' year level of study, University, length of placement, and gender did not influence inclusion in the study. While a range of potential sites for inclusion were initially identified, participant numbers in rural hospitals were limited by staffing and recruitment issues, which in turn reduced the capacity for staff to offer clinical placements.

At the time the study commenced, only two sites (CEs and students on placement at one regional hospital and one rural hospital) were available to participate. Specifically, potential participants at the regional hospital were two occupational therapy CEs and two students in the orthopaedic ward, and two occupational therapy CEs and one occupational therapy student in the rural hospital. Participants were invited to join the study by the primary investigator through face-to-face invitation.

\section{Intervention}

An overview of the processes of implementation of the CF for clinical education in occupational therapy has been previously described. ${ }^{16}$ Stages $1-5$ of the CF were conducted with occupational therapists in the health service prior to commencement of the student placement. While no formal consultations with university stakeholders were undertaken, information about the CF placement model was provided to the university when student placements were confirmed. During verbal discussions with university Clinical Education Liaison Managers about the CF model, agreement was reached that the model could support student skill development and meet competency elements on the SPEF-R

C The Internet Journal of Allied Health Sciences and Practice, 2018 
placement assessment tool. Students were not involved in the design of the model and were advised about the structure of the placement using the CF when they contacted the health service for details about their placement.

The CF 'taught, modeled, competent' approach was used to support student skill development in this study. In the first week of placement, all students were 'taught' background and theoretical information for nine CTls (Table 2) by a senior occupational therapist. The first day of training was attended face-to-face by all students. There were three subsequent training sessions each lasting approximately 2 hours with the student at the rural hospital participating via videoconference link to the training site. The 'taught' and 'modeled' components of the training for the nine CTIs listed in Table 2 were completed during the first week of placement. This involved didactic teaching of the tasks for the 'taught' component followed by demonstration via role-play or simulation for the 'modeled' component. Students then practiced the task and the trainer or peers provided feedback. Attempts were made, as much as possible, to use clinical treatment environments during the training, such as conducting the training in the ward bathroom and using a de-identified chart to practice information gathering. An additional two CTIs, required for service delivery in the orthopaedic ward, were 'taught and modeled' separately for students completing placements in that area. Following the 'taught and modeled' component of the training, students' clinical educators provided further "on the job" teaching, modeling, and provided feedback to enable students to develop competence in the clinical tasks. Students' competence in each of the tasks was assessed by the CEs observing them complete the task with a patient using a checklist written for each competency and contained in the CTI document.

Tasks identified in CF stage 2 were the most frequent occupational therapy service delivery tasks conducted in the orthopaedic ward across the continuum of patient care, therefore, the CTI tasks comprised much of the placement experience. As the occupational therapy rural generalist service delivery in the rural hospital was so diverse, the CF model formed one part of the placement experience for the student at the rural hospital. The structure of the CF placement model is similar to a traditional placement structure where students work alongside their $\mathrm{CE}$, however, it provides a more structured approach to teaching and learning clinical tasks and skills at the commencement of placement compared to usual placement learning approaches, which rely on learning through observation of CEs and less structured learning approaches. ${ }^{16}$

Table 2. Clinical task instructions (CTIs) completed during placement

\begin{tabular}{|c|c|}
\hline \multicolumn{2}{|c|}{ CTIs taught to all students } \\
\hline ○ & WTS02: When to Stop (Student Allocated task) \\
\hline o & A-AD01: Over toilet frame prescription \\
\hline o & A-AD02: Prescription/practice use shower chair/stool \\
\hline o & A-AD03: Prescription/practice use static commode \\
\hline ○ & A-AD06 Occupational therapy initial assessment \\
\hline o & A-AD07: Long handled devices - assessment and practice \\
\hline ○ & A-CP01: Cognitive Screen Montreal Cognitive Assessment (MOCA) \\
\hline ○ & A-CP02: Six item cognitive impairment test (6CTI) \\
\hline$\circ$ & A-MT01: Assessment and practice car transfer \\
\hline \multicolumn{2}{|c|}{ Additional CTIs taught to students completing placements in the orthopaedic ward } \\
\hline O & $\begin{array}{l}\text { A-NM01: Inpatient review of major orthopaedic pre-admission (MOPS) } \\
\text { (recommendations and development of treatment plan) }\end{array}$ \\
\hline ○ & A-AD04: Acute inpatient services - Discharge planning \\
\hline
\end{tabular}

Note: Code for CTI refers to Queensland Health CTI numbering classification 
Students achieved competency sign-offs using the competency assessment in the CTI for all frequently presenting tasks across both the regional and rural site. Competency sign off was achieved when the students competently demonstrated use of the clinical skill with patients. Students did not achieve competency sign-offs for cognitive assessments, Montreal Cognitive Assessment (MOCA) and the Six item cognitive impairment test (6CIT), as these tasks were less frequently used in their practice areas. Thus, the students did not have the opportunity to be observed competently using these skills during patient care.

\section{Data Collection}

Data collection tools used in the study included focus group discussions (FGD) and in-depth interviews (IDI). The interview schedule for FGDs and IDIs was developed by researchers with open-ended prompt questions to guide semistructured interviews. The questions were trialed during a pilot study. The primary investigator was known to all study participants; therefore, a focus group facilitator external to the health service was employed to limit the potential of bias. Separate focus groups were held for students and CEs. FGD and IDI were conducted in private rooms on hospital grounds with only participants and facilitator present. Rural occupational therapists and the student participated in the FGD using videoconference technology which was familiar to all participants. The data collection period was limited due to grant funding constraints.

\section{Data Analysis}

The FGD and IDI were used to explore participant opinions on the application of CF in clinical education. ${ }^{18}$ Focus group sessions were audio recorded and each focus group lasted approximately 60 minutes. Recorded discussions were transcribed verbatim. Following transcription, two investigators independently read the transcripts to gain broad understanding and develop initial codes. Coding was completed by hand and based on naturally occurring themes arising from the data. Codes were collated into themes with similar topics grouped together and consideration taken of interrelationships between codes. Investigators jointly compared the themes and re-examined the data to achieve consensus. Participants were invited to review coded transcripts to ensure accuracy.

\section{RESULTS AND DISCUSSION Study participants}

A total of 3 occupational therapy students and 3 occupational therapy CEs participated in one FGD (Table 3). All CE and student participants were female, and all three students were in their final year of study at the same university. One student completed an IDI in the final ( $\left.5^{\text {th }}\right)$ week of placement. The remaining two students participated in a FGD in their final $\left(10^{\text {th }}\right)$ week of placement. Four CEs were invited to participate in a FGD in the week following each student's departure, with three CEs participating. 
Table 3. Study participants

\begin{tabular}{|c|c|c|c|}
\hline Participant & Location & Placement descriptors & Comments \\
\hline CE 1 & $\begin{array}{l}\text { Regional hospital } \\
\text {-Orthopaedic ward }\end{array}$ & $\begin{array}{l}\text { Shared supervision of } 2 \times 4^{\text {th }} \text { year } \\
\text { students - } 5 \text { week and } 10 \text { week } \\
\text { block placements }\end{array}$ & $\begin{array}{l}\text { Students completing tasks only in } \\
\text { orthopaedic ward. CEs servicing } \\
\text { orthopaedic ward and outpatient } \\
\text { hand clinic }\end{array}$ \\
\hline CE 2 & $\begin{array}{l}\text { Rural hospital } \\
\text { (inpatient and } \\
\text { community case } \\
\text { load) }\end{array}$ & $\begin{array}{l}\text { Shared supervision of } 1 \times 4^{\text {th }} \text { year } \\
\text { student - } 10 \text { week block } \\
\text { placement }\end{array}$ & \\
\hline CE 3 & $\begin{array}{l}\text { Rural hospital } \\
\text { (inpatient and } \\
\text { community case } \\
\text { load) }\end{array}$ & $\begin{array}{l}\text { Shared supervision of } 1 \times 4^{\text {th }} \text { year } \\
\text { student - } 10 \text { week block } \\
\text { placement }\end{array}$ & \\
\hline Student 1 & $\begin{array}{l}\text { Regional hospital } \\
\text {-Orthopaedic ward }\end{array}$ & $\begin{array}{l}4^{\text {th }} \text { year student completing } 5 \\
\text { week block placement, } 2016 \text {. }\end{array}$ & $\begin{array}{l}\text { Student commenced training with } \\
\text { other students, but completed } \\
\text { block at week } 5 \text { to complete } \\
\text { overseas placement for final } 5 \\
\text { weeks. }\end{array}$ \\
\hline Student 2 & $\begin{array}{l}\text { Regional hospital } \\
\text {-Orthopaedic ward }\end{array}$ & $\begin{array}{l}4^{\text {th }} \text { year student completing } 10 \\
\text { week block placement } 2016\end{array}$ & \\
\hline Student 3 & $\begin{array}{l}\text { Rural hospital } \\
\text { (inpatient and } \\
\text { community case } \\
\text { load) }\end{array}$ & $\begin{array}{l}4^{\text {th }} \text { year student completing } 10 \\
\text { week block placement } 2016\end{array}$ & \\
\hline
\end{tabular}

\section{FINDINGS}

This study explored CE and student perceptions about the application of the CF as a clinical education model with consideration of barriers and enablers to the implementation of the CF model and suggestions for future implementation. Five key themes were identified through qualitative analysis of the FGD and IDI data. These included 1) experience of new model, 2) adjustment to change in approach to placement model, 3) impact of Calderdale Framework Clinical Task Instructions, 4) impact of CF learning model on student confidence, and 5) impact of CF placement model on service delivery. A summary of CE and student perspectives derived from focus groups is shown in Table 4 and participant quotes have been provided in the discussion to illustrate themes. Results from the FGDs provided positive responses from CEs and students in relation to the implementation of the CF during a clinical placement. 
Table 4: Summary of clinical educator and student perspectives on the implementation of the Calderdale Framework in clinical education.

\begin{tabular}{|c|c|c|}
\hline Theme & Barriers & Enablers \\
\hline Experience of new model & $\begin{array}{l}\text { - Time taken in training } \\
\text { would have negatively } \\
\text { affected a shorter } \\
\text { placement } \\
\text { - Student reluctance about } \\
\text { role play training } \\
\text { - Impacts of rural service } \\
\text { differences on clinical } \\
\text { tasks }\end{array}$ & $\begin{array}{l}\text { - Training increased student } \\
\text { understanding of tasks } \\
\text { - Benefits of role play in } \\
\text { learning } \\
\text { - CE perception that CF model } \\
\text { would help a student who took } \\
\text { longer to develop } \\
\text { competency, helps to have } \\
\text { structured framework }\end{array}$ \\
\hline $\begin{array}{l}\text { Adjustment to change in } \\
\text { approach to placement } \\
\text { model }\end{array}$ & $\begin{array}{l}\text { - CEs need more } \\
\text { information about training } \\
\text { content } \\
\text { - Ward/site orientation } \\
\text { would have been better } \\
\text { earlier in placement to give } \\
\text { context to training }\end{array}$ & $\begin{array}{l}\text { - Increased predictability of } \\
\text { placement for students } \\
\text { - Helps students acquire } \\
\text { knowledge } \\
\text { - Training outside of clinical } \\
\text { context gave students } \\
\text { opportunity to ask clarifying } \\
\text { questions before contact with } \\
\text { patients }\end{array}$ \\
\hline $\begin{array}{l}\text { Impact of Calderdale } \\
\text { Framework Clinical Task } \\
\text { Instructions }\end{array}$ & $\begin{array}{l}\text { Framework useful, but } \\
\text { might be better to have } \\
\text { trainer from placement } \\
\text { area; CEs still modeled } \\
\text { task in ward environment }\end{array}$ & $\begin{array}{l}\text { - Benefits of having CTI booklet } \\
\text { to refer to } \\
\text { - Students develop clear } \\
\text { understanding of clinical } \\
\text { processes in workplace } \\
\text { - CF Model works well with } \\
\text { repetitive caseloads }\end{array}$ \\
\hline $\begin{array}{l}\text { Impact of CF learning } \\
\text { model on student } \\
\text { confidence }\end{array}$ & $\begin{array}{l}\text { CF taught-modeled- } \\
\text { competent model is } \\
\text { designed to focus on } \\
\text { clinical skills not } \\
\text { professional skills } \\
\text { - Difficulties with simulation } \\
\text { and role play (e.g. student } \\
\text { peers don't have pain) }\end{array}$ & $\begin{array}{l}\text { - Students like taught-modeled- } \\
\text { competent approach- helped } \\
\text { develop confidence } \\
\text { - Benefits of practice and role } \\
\text { play before going to the ward } \\
\text { - Gives students an idea of } \\
\text { what to expect on the ward } \\
\text { - Students felt that the } \\
\text { increased knowledge acquired } \\
\text { before seeing patients } \\
\text { reduced their sense of being } \\
\text { overwhelmed. }\end{array}$ \\
\hline $\begin{array}{l}\text { Impact of CF placement } \\
\text { model on service delivery }\end{array}$ & $\begin{array}{l}\text { Need to condense down } \\
\text { training; repetitive, } \\
\text { significant time taken to } \\
\text { complete training prior to } \\
\text { patient contact }\end{array}$ & $\begin{array}{l}\text { - Time savings, cuts down time } \\
\text { CEs need to train students } \\
\text { - Support to CE workload } \\
\text { - Students contribute to patient } \\
\text { care }\end{array}$ \\
\hline
\end{tabular}

\section{Experience of New Model}

(c) The Internet Journal of Allied Health Sciences and Practice, 2018 
All three CEs and three student participants reported that the use of CF in clinical placement had been a positive experience. The initial time spent training in CTIs was valued by students as a way to understand the clinical task before they saw patients. This is consistent with literature suggesting that novices favor adherence to 'rules' rather than understanding context. 8,19 Students reported that role-playing helped them to '(get) comfortable with phrases that you would use on the ward' STUDENT 2. Some students reported feeling awkward completing the role plays with a trainer they had only just met. The use of the CF CTIs as a training resource was considered by all students to provide a more thorough approach to providing theoretical knowledge during training. All three students considered the CTls, which provided scripted prompts and steps to follow for interventions, a useful resource to refer to during their placement and for future reference. All three students acknowledged the trainer not being from the immediate work area to be positive in that it gave them a different perspective on completing a task. The two students in the orthopaedic ward, however, noted that they modeled more from their CE than from the initial training and the CEs identified the need to further model the tasks on the ward. All CEs and students identified differences in the CTIs required for a rural generalist caseload, with the frequency of completion of some tasks identified for the training being much less at the rural site.

\section{Adjustment to Change in Approach to Placement Model}

Two of the students noted similarities between the CF training approach and experiences in other placements. For some CEs, the CF model followed the usual placement progression but with the bonus of students receiving context specific training as background knowledge. The issue of increased demand on CE workload, when supervising students, has been examined by several authors ${ }^{20-23}$ The CF approach was not considered by CEs to either save time or take extra time during the placement. The two rural CEs noted benefits for students who were completing the same tasks with patients with similar conditions. Providing multiple opportunities for students to practice interventions is considered an important transitional phase of learning to help students begin to consider how to support patients with a range of needs.

All three CEs noted the need for more information about the initial training in the CTIs to be provided to students by the occupational therapy trainer at the commencement of the clinical placement.

\section{Impact of Calderdale Framework Clinical Task Instructions}

The CF CTIs were valued by all three students as a resource they could refer to on placement and into the future. One student reported,

"...so now you can apply the theory in a much different way. I went back to the task instructions that were written down in the hard copy and looked over it knowing what it looks like with a patient." STUDENT 1.

Repetition and practice have been highlighted by numerous authors in the progression of skill development for novice learners. $6,8,19$

"But we were mainly giving them the same stuff every time, so the same conditions... So I think that was good for them because they were able to practice similar patients with similar conditions." CLINICAL EDUCATOR 1.

\section{Impact of CF Learning Model on Student Confidence}

The need for competent and confident practitioners in a changing work environment is well documented in the literature. ${ }^{24}$ For some authors, there is conflict of opinion on whether skills for practice should be taught at a university or in the workplace. ${ }^{25}$ One student reported the benefit of the CF model:

"It also gave us a sense of what the organization expected of us because I know that what the uni(versity) is giving us is really broad." STUDENT 1

(c) The Internet Journal of Allied Health Sciences and Practice, 2018 
All three students reported aspects of the model, such as role-play and practicing clinical tasks before patient contact, had increased their confidence. This is an important factor as literature suggests that many students identify anxiety about learning to perform new tasks. ${ }^{6}$ One student identified how the model increased her confidence through the CF process of competency sign-offs by the trainer and CEs. Gruppen et al. note the benefits of competency-based education in providing a framework for implementing education, which specifies performance standards, to determine if the learner has reached a standard of performance considered competent. ${ }^{26}$ All three students identified benefit of having the opportunity to role-play and practice a task before going to the ward. Practical sessions with demonstration and opportunities to practice skills in a safe environment were noted by Naidoo and van Wyk as strategies that positively influenced learning on placement. ${ }^{27}$ One student said,

"I did like that we got the chance to practice before we went to the ward. I think that made a huge difference from, when we- then finally we first got to do it ourselves." STUDENT 1.

A student identified the similarities to the learning process in other placements, however also noted,

"Whereas here I was shown then practiced a little bit by myself with my (s) fellow student, then (trainer) would give us feedback which was good..." STUDENT 1.

Another student reported appreciating the 'taught, modeled, competent' approach used in the CF:

"I guess I really like the three steps because it means that you're really clear by the time it comes to you actually doing it, about what you're doing and why because you've observed it being done before in the first week. We've talked about it and then you've observed it being done and then you have the chance to practice it before you're assigned." STUDENT 3.

Teaching and learning strategies such as tutorials, demonstration, and practicing clinical skills were noted by students to be of high importance on placement. In addition, allowing students some independence, giving guidance, and modeling interventions was considered by students in Grenier's study as preferred teaching techniques. ${ }^{28}$

\section{Impact of CF Placement Model on Service Delivery}

The three students identified that participation in the CF had enabled them to be more prepared for practice. One student said,

"It also gave us an idea of what to expect when we go on [to the] ward." STUDENT 1, while another said, "I still feel we were probably more confident in the way that we were communicating because we had spare time to think about how to talk through the tasks and instructions we gave." STUDENT 2.

Two of students identified how the model enabled them to focus on patient care:

"We felt free to ask questions (in training) and all of that, whereas in a clinical setting with patients it could be a bit awkward or we'd have to wait until after we'd done it to feedback (to) our supervisor'... 'I think it made me feel a lot more confident in what I was doing and that probably helped me to be a bit more efficient and effective as well... Like instead of just trying to think how to convey it to the client." STUDENT 3.

All clinical educators identified that students had been able to contribute to patient service delivery. One CE reported,

"I think for us it was really helpful. We've seen a really big reduction in the workload, I suppose, as the placement progressed, because often the ward would have something like six (people undergoing) joint replacements at a time, and (student) by the end of it was really quite competent at doing those MOPS (Major Orthopaedic Pre-admission Screening) reviews. (Student) decided, clinically reasoning, what to do with them as well. So taking out six people off a list of 12 people is really quite massive. But it was really only beyond halfway." CLINICAL EDUCATOR 1

(c) The Internet Journal of Allied Health Sciences and Practice, 2018 
Another CE noted,

"It... saved a bit of time... if we're seeing someone and then they needed a piece of equipment, I could ask (Student), can you run over to the equipment room and get that for me. Give it to them, do the loan form." CLINICAL EDUCATOR 2.

These findings are supported by several studies which show students contributed positively to service delivery while on placement. ${ }^{21,29,30}$

\begin{abstract}
Limitations
There are several factors, which should be considered related to the findings of this study. Only a small number of participants were available for inclusion in this study. This pilot study consisted of three CEs and three student participants because of difficulties in recruiting and budget constraints affecting staffing and recruitment. Consequently, this limits the inferences that can be drawn from the findings. Based on placement allocation processes, students involved in this study were all from the same university and same year level. This study examined and applied the CF at two sites with two different caseloads. The caseload diversity may also limit the generalizability of the findings. The primary researcher in this study was known to all participants given their role in supporting and managing clinical education and student placements in the health service. The application of the CF in clinical education was conceptualized by the primary researcher and may have biased participant contribution to the study. An independent facilitator was employed to conduct focus groups to reduce potential bias. The limitations of this pilot study highlight the need for further examination of the application of CF in clinical education contexts.
\end{abstract}

\title{
CONCLUSIONS
}

Based on feedback provided in the FGD, the model was accepted by both students and CEs as a way of supporting student skill development, confidence, and safe patient service delivery. Features of the CF model supporting student skill development, such the use of the taught, modeled, competent approach to skill acquisition, role-play and feedback from the trainer were valued by students. The use of a scaffolded skill development approach, including initial scripts and learning opportunities for students to observe modeling of clinical tasks, supports the notion of the progression from novice leaner to advanced beginner. ${ }^{19}$ In addition, the advantages of focusing on a narrow set of skills and learning these in conditions structured to reduce error was recognized by study participants. ${ }^{19}$ While this study did not specifically focus on the development of clinical reasoning, the CF CTIs include a clinical reasoning tool and CEs noted the students' use of clinical reasoning in service delivery. Both students and CEs identified the contribution of the model to student confidence in both service delivery and communication with patients. Student contribution to patient service delivery, while not the focus of this study, was noted by CEs and reflected as increased activity levels in patient service delivery data compared to a conventional placement model.

Study participants provided several suggestions for trial in relation to future implementation of the CF in clinical education. Students suggested that training is undertaken following orientation to the placement environment and caseload. It was suggested that videos of the clinical task being modeled by an occupational therapist in an authentic environment with a patient, could be used to build a bank of training resources. One CE suggested that training videos would provide the added benefits of time efficiency and an opportunity to customize the CTls taught to the needs of the practice area.

This pilot study has described the application of the CF in clinical placement for occupational therapy students. The authors suggest that the CF could be considered as a model in clinical education supporting student learning and skill development for occupational therapy and other allied health professions through application of CF stages. Further investigation of this model of clinical education with larger samples of allied health students on clinical placement is recommended. Further areas of exploration could include examination of the outcomes both from clinical educator and student perspectives as well as outcomes of service delivery statistics and patient experience.

(c) The Internet Journal of Allied Health Sciences and Practice, 2018 


\section{REFERENCES}

1. Brown $T$, Mckinstry CE, Gustafsson $L$. The need for evidence and new models of practice education to meet the 1000 hour requirement. Aust Occup Ther J. 2016 Oct;63(5):352-6. doi: 10.1111/1440-1630.12239 [PMID: 26607851]

2. Turpin M, Fitzgerald C, Rodger S. Development of the Student Practice Evaluation Form Revised Edition Package. Aust Occup Ther J. 2011 Apr;58(2):67-73. doi: 10.1111/j.1440-1630.2010.00890.x [PMID: 21418228]

3. Hood W. University Occupational Therapy Practice Education Network, UOTPENQ member. Personal Communication. October, 12, 2017.

4. State of Queensland, 2013. Blueprint for Better Healthcare in Queensland. State of Queensland, Queensland Health.

5. Dreyfus SE. The five-stage model of adult skill acquisition. Bull Sci Tech Soc. 2004 Jun;24(3):177-81. doi: 10.1177/0270467604264992

6. Benner P. Using the Dreyfus Model of skill acquisition to describe and interpret skill acquisition and clinical judgment in nursing practice and education. Bull Sci Tech Soc. 2004 Jun;24(3):188-99. doi: 10.1177/0270467604265061

7. Carraccio CL, Benson, BJ, Nixon LJ, Derstine, PL. From the educational bench to the clinical bedside: translating the Dreyfus developmental model to the learning of clinical skills. Acad Med. 2008 Aug;83(8):761-7. doi: 10.1097/ACM.0b013e31817eb632 [PMID: 18667892]

8. Spalding NJ. Improving practice through involvement in action research. Int J Ther Rehabil. 2009 Sep;16(3):1308. doi: $10.12968 / i$ tr. 2009.16.3.40065

9. Schell B, Schell JW. Clinical and Professional Reasoning in Occupational Therapy. Philadelphia: Wolters Kluwer Health/Lippincott Williams \& Wilkins; 2008.

10. Unsworth C, Baker A. A systematic review of professional reasoning literature in occupational therapy. $\mathrm{Br} \mathrm{J}$ Occup Ther. 2016 Jan; 79(1):5-16. doi: 10.1177/0308022615599994

11. Nancarrow S, Moran A, Wiseman L, Pighills AC, Murphy K. Assessing the implementation process and outcomes of newly introduced assistant roles: a qualitative study to examine the utility of the Calderdale Framework as an appraisal tool. J Multidiscip Healthc. 2012;5:307-17. doi: 10.2147/JMDH.S35493 [PMID: 23271913]

12. Patterson SA, Comans TA, Pitt EL, Currin ML. Streamlining clinical practice in an Australian community rehabilitation service using The Calderdale Framework. Int J Ther Rehabil. 2015 Sep;22(9):434-41. doi: 10.12968/ijtr.2015.22.9.434

13. Pighills AC, Bradford M, Bell K, Flynn LJ, Williams G, et al. Skill-sharing between allied health professionals in a community setting: A randomised controlled trial. Int J Ther Rehabil. 2015 Nov;22(11):524-34. doi: 10.12968/ijtr.2015.22.11.524

14. Smith R. Duffy J. Developing a competent and flexible workforce using the Calderdale Framework. Int J Ther Rehabil. 2010 Sep;17(5):254-62. doi: 10.12968/ijtr.2010.17.5.47844

15. Kaltner M, Murtagh D, Bennetts M, Pighills A, James J, Scott A. Randomised controlled trial of a transprofessional healthcare role intervention in an acute medical setting. J Interprof Care. $2017 \mathrm{Mar} ; 31(2): 190-$ 8. doi: 10.1080/13561820.2016.1248237 [PMID: 28181844]

16. Furness L, Pighills AC, Ducat W, Tynan A. Implementation of a new model of clinical education for regional occupational therapy student clinical placements. Aust Health Rev. 2016 Oct;41(5)546-52. doi: 10.1071/AH16044 [PMID: 27632211]

17. Creswell JW. Research Design: Qualitative, Quantitative, and Mixed Methods Approaches. Thousand Oaks: Sage; 2014.

18. Prince KJ, Van De Wiel M, Scherpbier AJ, Cess P, Boshuizen HP. A qualitative analysis of the transition from theory to practice in undergraduate training in a PBL-medical school. Adv Health Sci Educ Theor Pract. 2000;5(2):105-16. doi: 10.1023/A:1009873003677 [PMID: 12386467] 
19. Peña ED, Kiran S. In defense of cookbooks: from novice to competent clinician. Top Lang Disord. 2008 JulSep;28(3):242-58. doi: 10.1097/01.TLD.0000333599.30468.9d

20. Shalik H, Shalik LD. The occupational therapy level II fieldwork experience: estimation of the fiscal benefit. Am J OccupTher. 1998 Mar;42(3):164-8. [PMID: 3128115]

21. Rodger S, Stephens E, Clark M, Ash S, Hurst C, Graves N. Productivity and time use during occupational therapy and nutrition/dietetics clinical education: a cohort study. Plos One. 2012;7(8):e44356. doi: 10.1371/journal.pone.0044356 [PMID: 22952964]

22. Thomas Y, Dickson D, Broadbridge J, Hopper L, Hawkins R, et al. Benefits and challenges of supervising occupational therapy fieldwork students: supervisors' perspectives. Aust Occup Ther J. 2007 Dec;54(s1):S2-12. doi: $10.1111 / j .1440-1630.2007 .00694 . x$

23. Lopopolo RB. Financial model to determine the effect of clinical education programs on physical therapy departments. Phys Ther. 1984 Sep;64(9):1396-402. [PMID 6433370]

24. Derdall $\mathrm{M}$, Olson $\mathrm{P}$, Janzen $\mathrm{W}$, Warren $\mathrm{S}$. Development of a questionnaire to examine confidence of occupational therapy students during fieldwork experiences. Can J Occup Ther. 2002 Feb;69(1):49-56. doi: 10.1177/000841740206900105 [PMID: 11852690]

25. Hummell J. Effective fieldwork supervision: occupational therapy student perspectives. Aust Occup Ther J. 1997 Dec;44(4):147-57. doi: 10.1111/j.1440-1630.1997.tb00769.x

26. Gruppen LD, Mangrulkar RS, Kolars JC. The promise of competency-based education in the health professions for improving global health. Hum Resour Health. 2012 Nov;10:43. doi: 10.1186/1478-4491-10-43 [PMID: 23157696]

27. Naidoo $D$, van Wyk J. Fieldwork practice for learning: Lessons from occupational therapy students and their supervisors. Afr J Health Prof Educ. 2016;8(1):37-40. doi: 10.7196/AJHPE.2016.v8i1.536

28. Grenier ML. Facilitators and barriers to learning in occupational therapy fieldwork education: student perspectives. Am J Occup Ther. 2015 Sep-Oct;69(S2):1-9. doi: 10.5014/ajot.2015.015180 [PMID: 26539680]

29. Leiken AM. Method to determine the effect of clinical education on production in a health care facility. Phys Ther. 1983 Jan;63(1):56-9. [PMID: 6849008]

30. Leiken AM, Stern E, Baines RE. The effect of clinical education programs on hospital production. Inquiry. 1983 Spring;20(1):88-92. [PMID: 6219950] 


\section{Appendix 1 \\ Clinical educator focus group questions}

Question 1

Reflecting on the use of Calderdale Framework to determine tasks appropriate for competency training and delegation to students on placement, can we talk about your experiences, impressions, thoughts and feelings about using this model?

Prompts

- What things have enabled you to utilise this model and what things have got in the way?

- $\quad$ Can you comment on the positives and negatives of the competency training model for students - for example, times when it worked for you and times when it didn't?

- What would have helped? / What could have been done differently?

- What advice would you have for another team embarking on this type of model?

- How did this model impact on your assessment of the student's learning?

\section{Question 2}

Reflecting on your clinical work with patients. Can we talk about your perceptions of the impact of the competency training and task allocation to the students' competency training model?
a. With respect to patient service delivery
b. With respect to access to occupational therapy service delivery to patients
c. With respect to patient flow and length of stay

\section{Question 3}

Reflecting on your role as a Clinical Educator. Can we talk about your perceptions of the impact of the competency training and task allocation to the students' competency training model on the CE workload?

- With respect to patient service delivery

- With respect to supporting student's learning

- With respect to student assessment

- With respect to timetabling

Question 4:

Do you have any suggestions for the implementation of student lead services at this hospital? 


\section{Appendix 2 \\ Student focus group questions}

Question 1:

Reflecting on the model of competency training and allocation of clinical tasks, can we talk about your experiences, impressions, thoughts and feelings about using this model?

General prompts:

- What things have enabled you to utilise this model and what things have got in the way?

- $\quad$ Can you comment on the positives and negatives of the competency training model for you as students - for example, times when it worked for you and times when it didn't?

- What would have helped? / What could have been done differently?

- What advice would you have for another team embarking on this type of model?

- $\quad$ How did this placement model impact on your learning? You may wish to consider how your learning experiences on this placement differed from other placement experiences.

\section{Question 2:}

Reflecting on your clinical work with patients. Can we talk about your perceptions of the impact of the competency training and delegation model?

- $\quad$ With respect to patient service delivery

- With respect to access to occupational therapy service delivery to patients

- With respect to patient flow and length of stay

Question 3:

Do you have any suggestions for the implementation of student lead services at this hospital?

Question 4:

Please feel free to add any other comments. 